\title{
Influence of Centrifugal Force on Filler Loading of Resin Composites
}

\author{
Naomi TANOUE 1 , Atsushi MIKAMI², Hiroaki YANAGIDA³, Mitsuru ATSUTA ${ }^{3}$, Rie NOMOTO ${ }^{4}$ \\ and Hideo MATSUMURA ${ }^{2}$ \\ ${ }^{1}$ Department of Specialized Dentistry, Nagasaki University Hospital of Medicine and Dentistry, 1-7-1, Sakamoto, Nagasaki \\ 852-8588, Japan \\ ${ }^{2}$ Department of Fixed Prosthodontics, Nihon University School of Dentistry, 1-8-13, Kanda-Surugadai, Chiyoda-ku, Tokyo 101- \\ 8310, Japan \\ ${ }^{3}$ Division of Fixed Prosthodontics and Oral Rehabilitation, Nagasaki University Graduate School of Biomedical Sciences, 1-7- \\ 1, Sakamoto, Nagasaki 852-8588, Japan \\ ${ }^{4}$ Department of Dental Engineering, Tsurumi University School of Dental Medicine, Yokohama, Kanagawa 230-8501, Japan \\ Corresponding author, Naomi TANOUE E-mail:t-naomi@net.nagasaki-u.ac.jp
}

Received January 18, 2006/Accepted August 29, 2006

\begin{abstract}
This study examined the influence of centrifugal force on the filler loading of composites using a light-polymerizing apparatus combined with a centrifuge. To assess uneven filler particle distribution resulting from specimen rotation, two lowviscosity composites (Palfique Estelite LV and Revolution Formula 2) were placed in test tubes, centrifuged, and subsequently light-polymerized with the apparatus. After each specimen was sliced into four disks (2-mm thickness), the inorganic filler content and Knoop hardness number (KHN) of each disk were determined. The results suggested that filler loading of composites could be increased by application of centrifugal force if the filler and monomer components were properly arranged.
\end{abstract}

Key words: Centrifugal force, Composite, Light-polymerizing apparatus

\section{INTRODUCTION}

In 1977, the American Dental Association classified dental composites into two types: Type 1 comprised those of chemically polymerized materials, and Type 2 those of external-energy-activated materials ${ }^{1)}$. Since then, dental composites have undergone strength improvements to enable them to perform better in large stress-bearing applications. In the early 1980s, composite materials were classified in another way that took account of particle size, manufacturing technique, and filler composition ${ }^{2)}$. Currently, composite materials are still undergoing development and refinement aimed to enhance their mechanical properties, wear resistance, and color stability.

Filler loading plays an important role in the mechanical properties of composite materials. As a result, total filler content in composite materials has increased to improve flexural strength and modulus ${ }^{3-6)}$, hardness ${ }^{4)}$, and fracture toughness ${ }^{4,7-9)}$. Modifications to filler morphology and components have also markedly influenced the recent developments of composite materials ${ }^{4)}$.

Of late, filler particles have become smaller due to technological advances in the field of dentistry. Tanoue et $a{ }^{10}{ }^{10}$ reported that a microfilled composite exhibited a smoother surface than composites that included macrofillers after toothbrush-dentifrice abrasion. Further, Turssi et $a .^{11)}$ reported that a nanofilled composite exhibited low pre-testing roughness and wear regardless of the finishing/polishing technique. For denture teeth, a nanocomposite tooth is reported to be harder and more wear-resistant than the usual acrylic teeth, but not significantly different from most crosslinked or microfilled composite teeth ${ }^{12)}$.

In general, it is difficult to industrially fabricate highly filled dental composites with small filler particles. Against this background, the authors designed a new laboratory polymerizing apparatus with the aim of increasing filler loading in composites. If filler particles - with a specific gravity greater than that of the resin matrix - could be concentrated by centrifugal force, higher filler loadings might be possible by using a centrifugal machine in the laboratory. This study therefore sought to investigate the fabrication of highly filled composite materials using centrifugal force. Accordingly then, we also reported on the structure of our trial centrifugal apparatus.

\section{MATERIALS AND METHODS}

\section{Centrifugal polymerizing apparatus}

A centrifugal light-polymerizing apparatus (Octothunder, Toho Dental Products, Saitama, Japan) was tentatively manufactured (Fig. 1). Three halogen lamps (150 W each) were placed at the bottom of the apparatus as light source. A rotator with four holes for test tubes was placed above the lamps. The unit was also equipped with a speed controller, a fan, and switches for rotation and light 
exposure timekeeping. Rotation speed was controlled within a range of $0-1,500 \mathrm{rpm}$, and light irradiation was possible before or during rotation. Details of the polymerizing apparatus are shown in Table 1 .

\section{Composite materials}

Two light-activated low-viscosity composites (Palfique Estelite LV High Flow (PE), A3, Tokuyama Dental Corp., Tokyo, Japan; Revolution Formula 2 (RF), Kerr/Sybron, Orange Co., USA) were selected for this study. The PE material included a silica-zirconia filler (68 wt\%) with two particle sizes of 0.1 and 0.4 $\mu \mathrm{m}$, while the $\mathrm{RF}$ material contained barium glass and synthetic silica fillers (55 wt\%) with particle size of $1 \mu \mathrm{m}$. Both materials contained 2,2-bis [4- (2-hydroxy-3-methacryloxy propoxy) phenyl] propane (Bis-GMA) and triethyleneglycol dimethacrylate (TEGDMA).

The composite materials were filled into four translucent polypropylene test tubes with an opening of $9 \mathrm{~mm}$ diameter until the height of the composite was $10 \mathrm{~mm}$. The test tubes were then rotated at 1,500 rpm for 120 minutes. For the last 30 minutes, the material was irradiated.

The polymerized composite cylinder was removed from the test tube and stored in water at $37^{\circ} \mathrm{C}$ for 24 hours to complete post-irradiation hardening ${ }^{13,14)}$. The composite cylinder was then mounted in an Isomet low-speed saw (No.11-1280-170, Buehler Ltd., Lake Bluff, IL, USA) with a diamond wafering blade
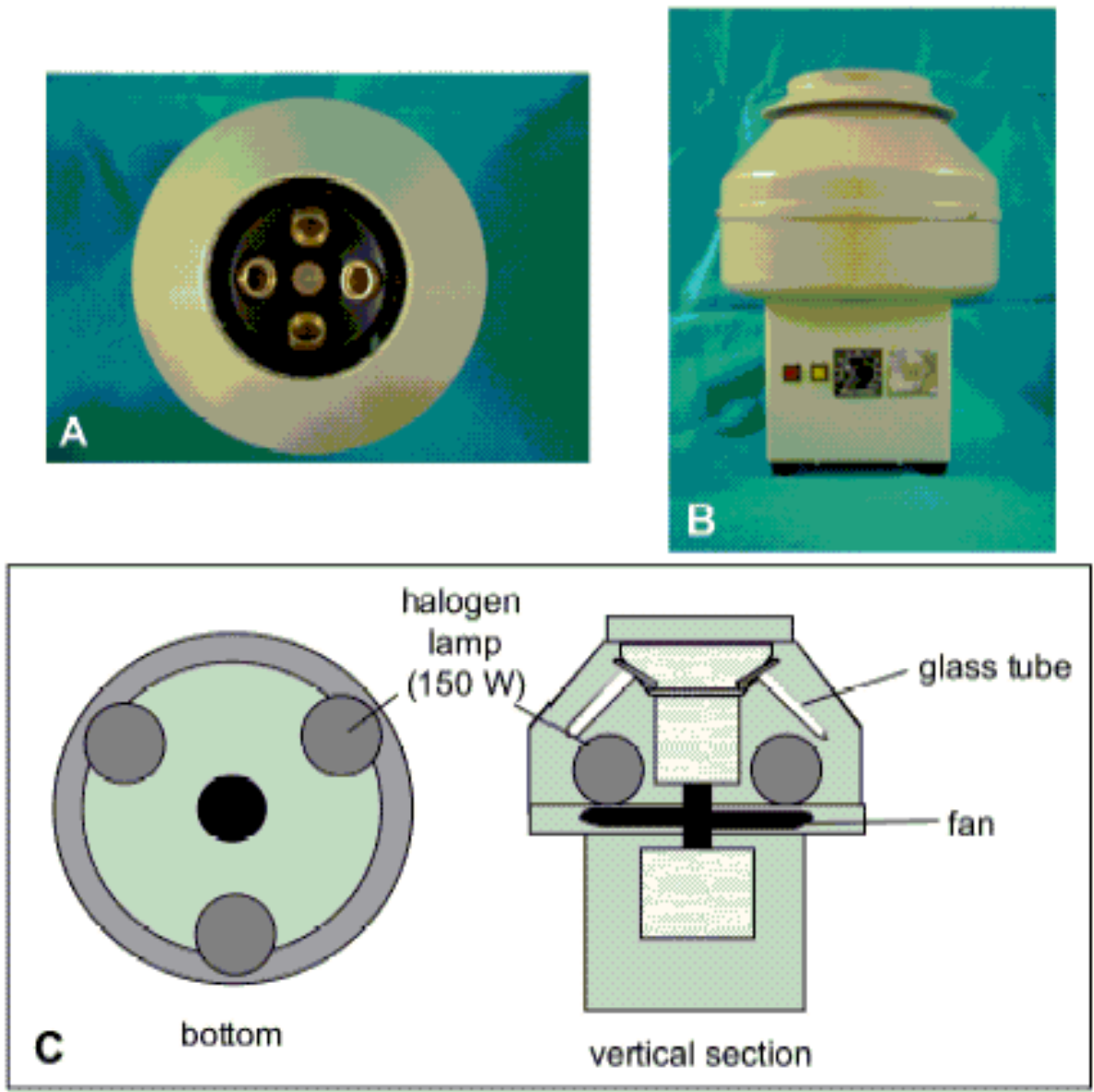

Fig. 1 A centrifugal light-polymerizing unit. A: Upper view without lid; B: Frontal view; C: Schematic representation of the apparatus.

Table 1 Details of centrifugal light-polymerizing apparatus (Ortothunder).

\begin{tabular}{lll}
\hline Light source & Halogen lamps & $150 \mathrm{~W} \times 3$ \\
Rotation time & $0-120 \mathrm{~min}$ & (controllable) \\
Exposure time & $0-120 \mathrm{~min}$ & (controllable) \\
Rotation speed & $0-1,500 \mathrm{rpm}$ & (controllable) \\
Specimen tube & $10 \mathrm{~mL} \times 4$ & \\
Manufacturer & Toho Dental Products, Saitama $336-0034$, Japan \\
\hline
\end{tabular}


(No.11-4244, Buehler Ltd.), and sectioned to achieve five disk-shaped specimens of $2.0 \mathrm{~mm}$ in height (Fig. 2). Among the five specimen disks, four point side disks of $0,2,4$, and $6 \mathrm{~mm}$ were evaluated.

\section{Filler content}

To assess the uneven distribution of filler particles resulting from sample tube rotation, the inorganic filler content was examined at each depth. First, the weight of each specimen was recorded and each disk was then incinerated at $600^{\circ} \mathrm{C}$ for 30 minutes using an incinerator (TMF 2000, J. Morita Corp., Suita, Japan). Filler content was calculated from the original weight of each specimen and the weight of the inorganic filler remaining after the polymer matrix became ash.

\section{Knoop hardness test}

The top surface of each increment disk was ground with \#600, \#1,000, and \#1,500 silicon carbide papers and polished with felt and $0.3-\mu \mathrm{m}$ alumina to produce a smooth, uniform surface. Knoop hardness was determined with a universal indenter (MVK-E Hardness Tester, Akashi Ltd., Yokohama, Japan). Knoop hardness number (KHN) was then calculated after a 50-g loading was applied for 30 seconds. Readings were made at five arbitrarily selected points on the top surface of each specimen.

\section{Statistical analysis}

For each composite material, the average and standard deviation values of filler content and KHN were calculated from five specimens at each depth. The results were primarily analyzed by Levene's test for equality of variances. When the results of the Levene's test showed homoscedasticity, values were analyzed by one-way analysis of variance (ANOVA) and post hoc Duncan's new multiple range test with the value of statistical significance set at 0.05 for each material.

\section{RESULTS}

Application of Levene's test yielded results that showed homoscedasticity.

With the PE material, the filler content of $0 \mathrm{~mm}$ increment disk was statistically $(p<0.05)$ the greatest among the four increments. The filler contents of 4 and $6 \mathrm{~mm}$ increments were not significantly different. Fig. 3 shows the filler content results at the four depths, while Fig. 4 shows the KHN test results. The KHN of $0 \mathrm{~mm}$ increment disk was also statistically $(\mathrm{p}<0.05)$ the greatest among the four increments.

With the RF material, the KHN of $0 \mathrm{~mm}$ increment disk was also statistically $(p<0.05)$ the greatest among the four increments. However, the filler content of $0 \mathrm{~mm}$ increment disk was not statistically ( $p>0.05)$ different from $2 \mathrm{~mm}$ and $4 \mathrm{~mm}$ increments. Figs. 5 and 6 show the filler content and KHN test results of the $\mathrm{RF}$ material respectively.

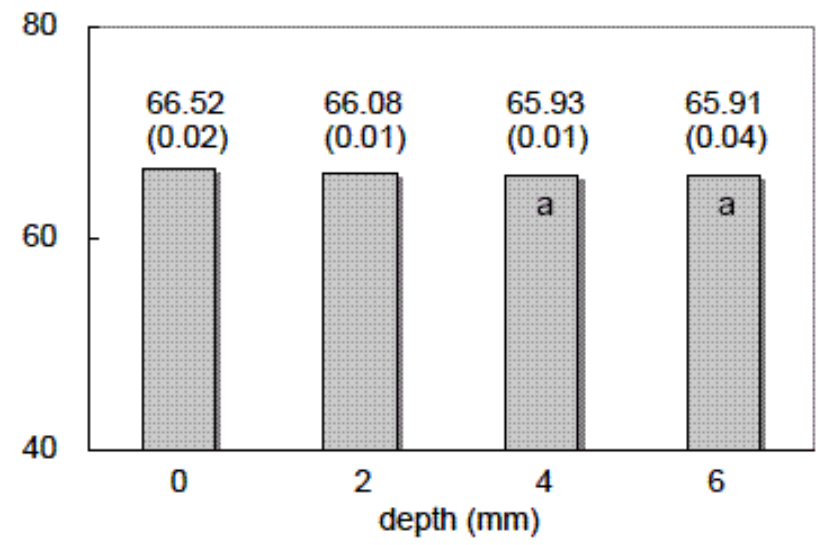

Fig. 3 Analysis of filler content for PE material at each depth. An identical letter indicates that values are not statistically different $(\mathrm{p}>0.05)$.

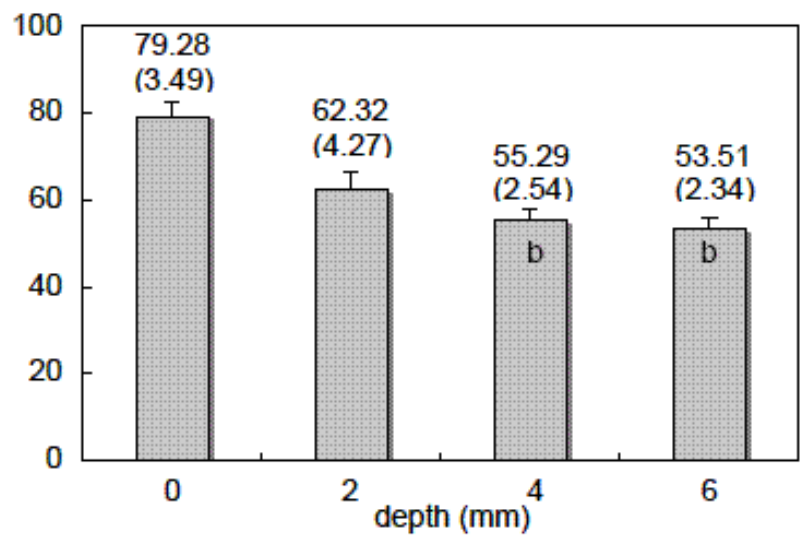

Fig. 4 Results of hardness testing for PE material at each depth. An identical letter indicates that values are not statistically different $(\mathrm{p}>0.05)$.

Fig. 2 Specimen preparation. 


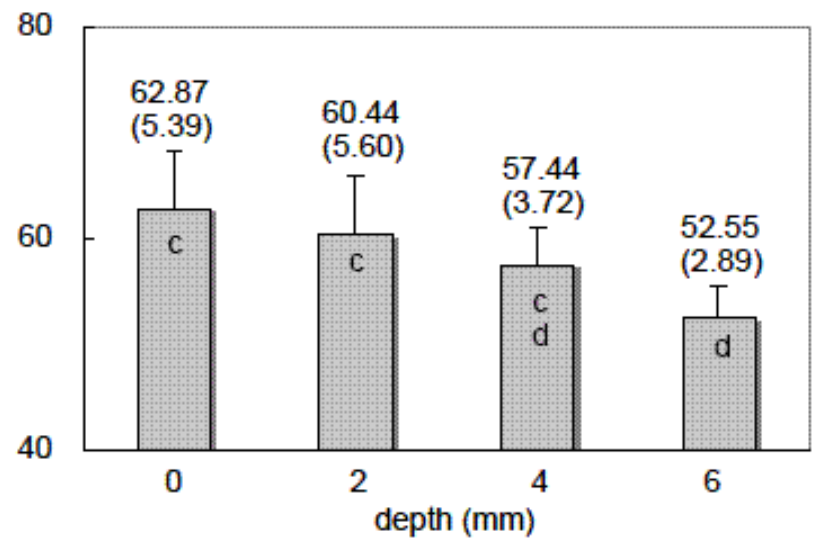

Fig. 5 Analysis of filler content for RF material at each depth. An identical letter indicates that values are not statistically different $(p>0.05)$.

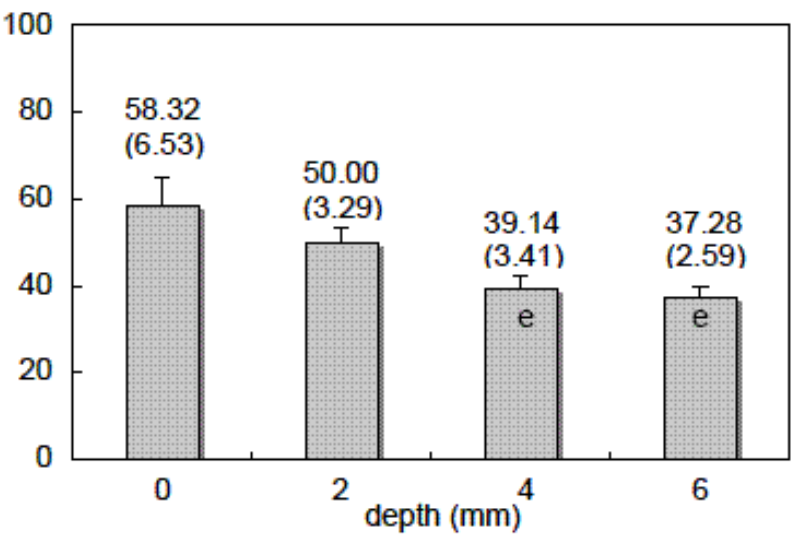

Fig. 6 Results of hardness testing for RF material at each depth. An identical letter indicates that values are not statistically different $(p>0.05)$.

\section{DISCUSSION}

The common definition of "centrifugal force" is that it is a fictitious force that appears to act on an object when its motion is viewed from a rotating frame of reference. An object traveling in a circle behaves as if it is experiencing an outward force. This centrifugal force depends on the mass of the object, the speed of rotation, and the distance from the center.

Since it has been found that the filler - rather than the resinous matrix - exerts a greater influence on the physical and mechanical properties of composite materials, high filler loadings have been experimented with or employed ${ }^{15)}$. Indeed, filler concentration plays a prominent role in determining the properties of a composite material. The advantages of highly filled composite materials are well known not only from in vitro investigations, but also from clinical practice.

The centrifugal light-polymerizing unit of the current study was developed to investigate whether a centrifugal force would be useful to concentrate filler particles in unpolymerized composite materials. This study showed that inorganic filler loading in a composite could be increased using the herein-developed centrifugal unit. Filler particles were thought to be moved to the circumferential edge of the test tubes by the centrifugal force, and consequently the filler content at the edge increased. With the PE material, the KHN results were related to the filler content (Figs. 3 and 4), since it has been reported that positive correlations were found between volume fraction of filler and Knoop hardness number, as well as between volume fraction of filler and diametral tensile strength ${ }^{16)}$. With the RF material, however, the filler content result did not strictly correlate with the KHN result. It seemed that with low-viscosity composites, the chemical composition might have an effect on filler movement - although this result leaves room for various other interpretations.

It was demonstrated that centrifugal force was effective for fabrication of highly filled composite materials. If such a force can be utilized to concentrate filler particles smaller than those used in the current study, composite materials with significantly improved properties and smooth surfaces might be fabricated with a centrifugal polymerizing unit. Nevertheless, our pilot study showed that the force produced by the herein-developed unit was not effective in concentrating the filler in a conventional lightactivated composite for direct restorations, but only effective with a low-viscosity "flowable" composite. For clinical effectiveness with conventional composites, the unit needs to be improved so that a larger centrifugal force can be produced by the laboratory unit. Furthermore, future studies should also reveal how centrifugal filler loading can be exploited in clinical practice.

\section{ACKNOWLEDGEMENTS}

This study was supported in part by Grants-in-aid for Scientific Research (Nos.B(2) 18390525 and B(2) 16791210) from the Japan Society for the Promotion of Science (JSPS).

\section{REFERENCES}

1) New American Dental Association specification no.27 for direct filling resins. Council on Dental Materials and Devices. J Am Dent Assoc 1977; 94: 1191-1194.

2) Lutz F, Phillips RW. A classification and evaluation of composite resin systems. J Prosthet Dent 1082; 50: 480488.

3) Willems G, Lambrechts P, Braem M, Celis JP, Vanherle G. A classification of dental composites according to their morphological and mechanical characteristics. Dent Mater 1992; 8: 310-319.

4) Kim KY, Ong JL, Okuno O. The effect of filler loading and morphology on the mechanical properties of 
contemporary composites. J Prosthet Dent 2002; 87: 642-649.

5) Ersoy M, Civelek A, L'Hotelier E, Say EC, Soyman M. Physical properties of different composites. Dent Mater J 2004; 23: 278-283.

6) Lohbauer U, Frankenberger R, Kramer N, Petschelt AJ. Strength and fatigue performance versus filler fraction of different types of direct dental restoratives. Biomed Mater Res B Appl Biomater 2005; 29 (76B): 114120 .

7) St Germain H, Swartz ML, Phillips RW, Moore BK, Roberts TA. Properties of microfilled composite resins as influenced by filler content. J Dent Res 1985; 64: 155160.

8) Braem M, Finger W, Van Doren VE, Lambrechts P, Vanherle G. Mechanical properties and filler fraction of dental composites. Dent mater 1989; 5: 346-348.

9) Johnson WW, Dhuru VB, Brantley WA. Composite microfiller content and its effect on fracture toughness and diametral tensile strength. Dent Mater 1993; 9: 9598.

10) Tanoue N, Matsumura H, Atsuta M. Wear and surface roughness of current prosthetic composites after toothbrush/dentifrice abrasion. J Prosthet Dent 2000; 84: 9397.

11) Turssi CP, Ferracane JL, Serra MC. Abrasive wear of resin composites as related to finishing and polishing procedures. Dent Mater 2005; 21: 641-648.

12) Suzuki S. In vitro wear of nano-composite denture teeth. J Prosthodont 2004; 13: 238-243.

13) Johnston WM, Leung RL, Fan PL. A mathematical model for post-irradiation hardening of photoactivated composite resins. Dent Mater 1985; 1: 191-194.

14) Leung RL, Adishian SR, Fan PL. Postirradiation comparison of photoactivated composite resins. J Prosthet Dent 1985; 54: 645-649.

15) Chung KH. The relationship between composition and properties of posterior resin composites. J Dent Res 1990; 69: 852-856.

16) Chung KH, Greener EH. Correlation between degree of conversion, filler concentration and mechanical properties of posterior composite resins. J Oral Rehabil 1990; 17: $487-494$ 